\title{
Investigations of the Effects of Synthetic Chemicals on the Endocrine System of Common Carp in Lake Mead, Nevada and Arizona
}

\author{
By Michael R. Rosen, Steven L. Goodbred, Reynaldo Patiño, Thomas J. Leiker, U.S. Geological Survey, and \\ Erik Orsak, U.S. Fish and Wildlife Service
}

\section{Introduction}

Lake Mead is the largest reservoir by volume in the United States and was created by the construction of the 221-meter high Hoover Dam in 1935 at Black Canyon on the lower Colorado River between Nevada and Arizona (fig. 1). Inflows of water into the lake include three rivers, Colorado, Virgin, and Muddy; as well as Las Vegas Wash, which is now perennial because of discharges from municipal wastewater treatment plants (Covay and Leiker, 1998) and urban stormwater runoff. As the population within the Las Vegas Valley began to increase in the 1940s, the treated effluent volume also has increased and in 1993 it constituted about 96 percent of the annual discharge of Las Vegas Wash (Bevans and others, 1996). The mean flow of Las Vegas Wash into Las Vegas Bay from 1992 to 1998 was about 490,000 $\mathrm{m}^{3} / \mathrm{d}$ (Preissler and others, 1999) and in 2001 increased to $606,000 \mathrm{~m}^{3} / \mathrm{d}$ (U.S. Bureau of Reclamation, 2001). The nutrient concentration in most areas of the lake is low, but wastewater discharged into Las Vegas Bay has caused an increased level of nutrients and primary productivity (aquatic plant and algal production) in this area of the lake (LaBounty and Horn, 1997). A byproduct of this increase in productivity has been the establishment of an important recreational fishery in Las Vegas Bay. However, concentrations of chlorophyll $a$ (a measure of algal biomass) have also increased (LaBounty and Horn, 1997). In the spring of 2001, parts of Lake Mead experienced massive algal blooms.

In addition to nutrient loading by wastewater, the presence of numerous synthetic chemicals in water, bottom sediments, and in fish tissue also has been reported (Bevans and others, 1996). Synthetic chemicals discharging into Las Vegas Bay and Lake Mead (fig. 1) originate from several sources that include surplus residential-irrigation water runoff, stormwater runoff, subsurface inflow, and tertiary treated sewage effluent discharging from three sewage-treatment plants. Chemicals detected in Las Vegas Wash and Bay environments include polycyclic aromatic hydrocarbons (PAHs), polychlorinated biphenyls (PCBs), organochlorine pesticides (including DDT and DDE), and "emerging contaminants" such as fragrances/ musks, flame retardants, triclosan and its breakdown products,

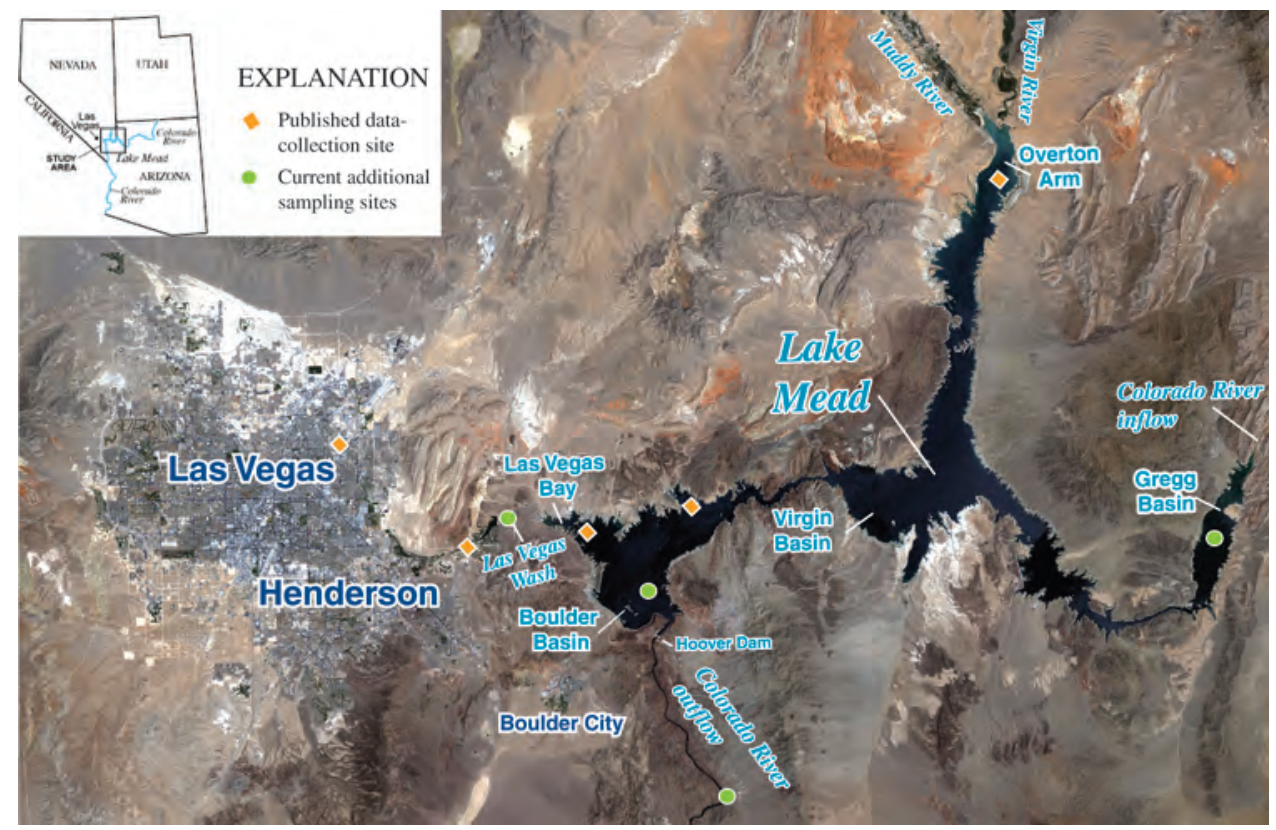

Figure 1. Location of sampling sites in published studies and proposed sites of synthetic chemicals and endocrine disruption in Lake Mead. 
personal care products, and pharmaceuticals (Bevans and others, 1996; Boyd and Furlong, 2002; Goodbred and others, 2007). Many of these compounds are able to interact with the endocrine system of animals and potentially cause reproductive impacts.

The National Park Service (NPS) manages Lake Mead National Recreation Area (LMNRA) with about 8 million yearly visitors including 500,000 anglers drawn to its worldclass recreational fishery. The U.S. Fish and Wildlife Service (FWS) provides management for the federally designated, endangered razorback sucker (Xyrauchen texanus) and for more than 180 species of migratory birds that utilize LMNRA surface waters. These multiple uses of surface water in the area demonstrate their vital importance to the LMNRA as well as the need to maintain the quality of water at levels that are adequate for these uses.

\section{Previous Studies of Endocrine Disruption}

A pilot study of Lake Mead was conducted in 1995 by the U.S. Geological Survey (USGS) and other Federal agencies including NPS and FWS. The purpose of this study

What is the endocrine system?

The endocrine system is composed of glands and tissues including the hypothalamus, pituitary, thyroid, adrenal, thymus, pancreas, ovaries, testes and others. These glands produce and release hormones into the bloodstream that travel to different parts of the body to control activities such as development, growth, reproduction and behavior. In some animal species, hormones also determine whether individuals become male or female during their early development.

\section{What is an endocrine disruptor?}

An endocrine disruptor is a natural or synthetic chemical that when taken up by an organism mimics, modifies or blocks the actions of hormones and disrupts normal physiology. Endocrine disruption occurs through alterations in the production or metabolism of hormones or their delivery in the bloodstream, or through direct actions on the tissues regulated by hormones. Synthetic chemicals known to cause endocrine disruption include diethylstilbestrol, ethynylestradiol, dioxins, PCBs, DDT/ DDE, perchlorate, flame retardants, some heavy metals, and others. A great deal of attention has been placed on endocrine disruptors with estrogenic (feminizing) activity.

\section{Why is knowledge of endocrine disruption important?}

At levels observed in the environment, many synthetic chemicals cause endocrine disruption in laboratory animals. Some field studies also have implicated endocrine disruption as a factor contributing to the impaired health of fish and wildlife populations.

For further information see National Institute of Environmental Health Sciences endocrine fact sheet http://www.niehs.nih.gov/oc/factsheets/pdf/endocrine.pdf

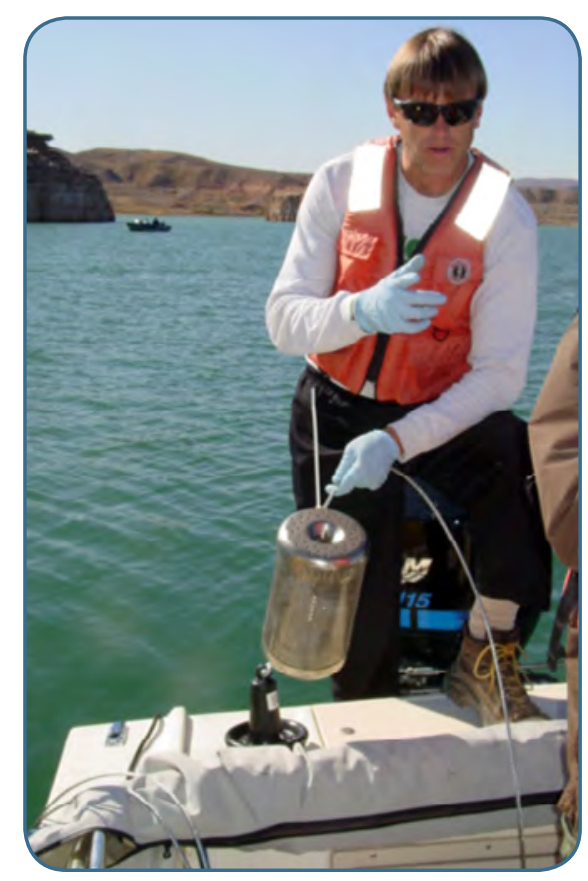

Hydrologist deploying passive samplers to sample organic compounds in Lake Mead.

was to investigate the potential for endocrine disruption in fish from the lake. Male and female common carp (Cyprinus carpio) were sampled in Las Vegas Wash, Las Vegas Bay and Callville Bay (fig. 1) once during the spawning season and analyzed for several endocrine and reproductive biomarkers. The study provided evidence suggesting that common carp from Las Vegas Wash and Bay exhibit endocrine disruption compared to fish from Callville Bay (Bevans and others, 1996). One notable finding was that male fish from Las Vegas Bay had significantly lower levels of the sex steroid hormone 11-ketotestosterone $(11 \mathrm{KT})$, a major androgen responsible for testicular function and sperm production in fishes (Schulz and Miura, 2002). Some evidence of endocrine disruption also was reported for female carp from Las Vegas Wash and Bay, such as altered ratios of sex hormones (Bevans and others, 1996).

The study of Bevans and others (1996) also provided evidence of a higher number and higher concentrations of environmental contaminants in lake sediment, water, and fish tissue from Las Vegas Bay and Wash relative to Callville Bay. The contaminants found included organochlorines (e.g., DDT and DDE), PAHs, furans, phthalates, phenols, and PCBs. Unlike Las Vegas Wash and Bay, Callville Bay has no point source discharges. Thus, the likely sources of synthetic chemicals in Las Vegas Wash and Bay are wastewater discharges and urban runoff flowing into Las Vegas Wash.

The report of Bevans and others (1996) raised concerns about the general quality of the aquatic habitat in the Las Vegas Wash and Bay regions of the lake and prompted a more thorough study. A follow-up collaborative study by the Department of the Interior (USGS; FWS; NPS; Bureau of Reclamation; University of Nevada, Las Vegas; University of Florida, Gainesville; Texas Tech University; and Nevada Division of Wildlife) was conducted in 1999-2000. The purpose of this study was to determine if the earlier evidence of endocrine disruption could be confirmed during a oneyear, full reproductive cycle (May 1999 to May 2000); and to 
further characterize environmental contaminants in Lake Mead including emerging compounds such as pharmaceuticals and personal care products. Data from this new study would also serve as a baseline to monitor the reproductive condition of fish in Lake Mead and as reference point for other research and monitoring studies of fish reproduction. The study compared observations made in Las Vegas Bay against those in a reference site, Overton Arm. Results for a number of biomarkers of reproductive condition were described by Patiño and others (2003). Male carp from Las Vegas Bay had smaller testes (gonadosomatic index) and higher levels of testicular macrophage aggregates (biomarkers of contaminant exposure)

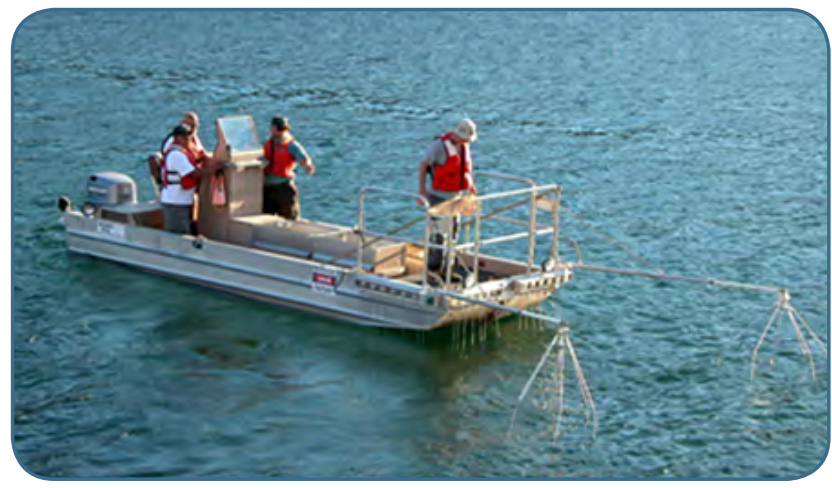

Specially designed electroshocking boat for sampling fish in Lake Mead.

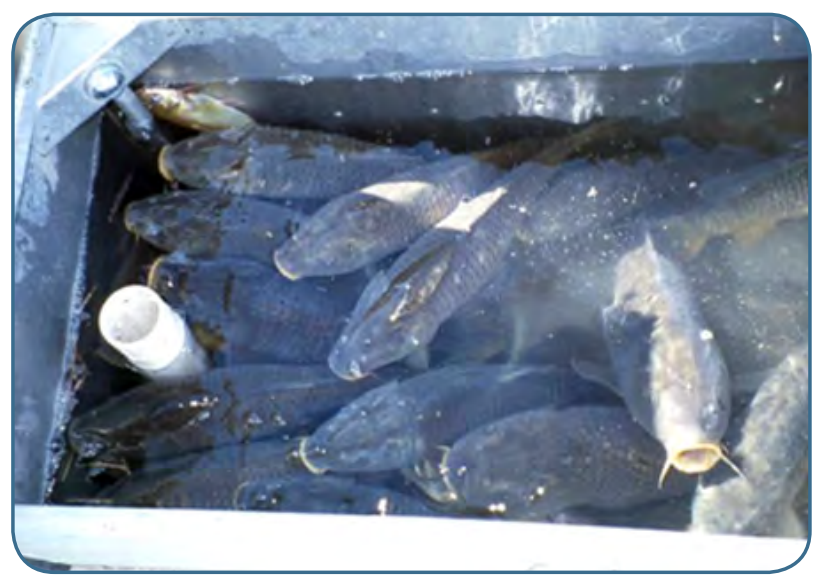

Common carp held in livewell before processing.

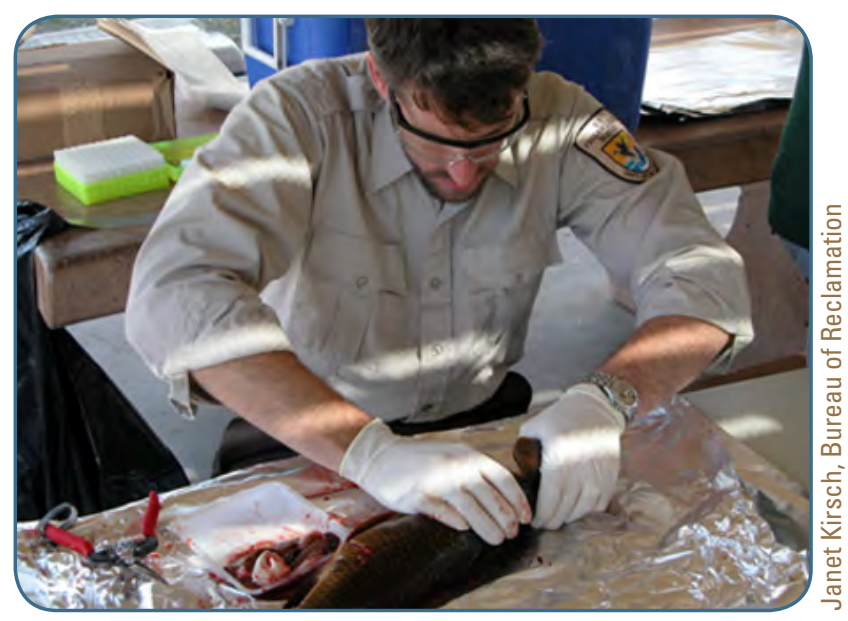

Biologist dissecting otoliths for aging common carp. throughout the year (Patiño and others, 2003). However, an assessment of female fish indicated that differences in reproductive biomarkers between Las Vegas Bay and Overton Arm could be explained by differences in water temperature profiles between the two sites through the annual cycle of seasons. This observation with female fish highlighted the need for seasonal sampling designs in field studies of endocrine disruption. Patiño and others (2003) concluded that, in 19992000, the aquatic environment in Las Vegas Bay specifically impacted the reproductive condition of male fish.

What environmental factors or synthetic compounds were responsible for altering the reproductive condition of male fish in the studies of Bevans and others (1996) and Patiño and others (2003)? Although the answer to this question is uncertain, results of a study by Covay and Beck (2001) indicated the presence of twice as many organic contaminants in sediment from Las Vegas Bay compared to Overton Arm (samples for this study were collected in 1998). They also found that the concentrations of pesticides and PCBs in sediment were over one order of magnitude higher at Las Vegas Bay. In addition, dioxins and furans were present in sediment of Las Vegas Bay but not Overton Arm (Covay and Beck, 2001). Goodbred and others (2007) recently reported the presence of degradation products of triclosan, a commonly used antimicrobial compound, in the same male fish from Las Vegas Bay that were analyzed by Patiño and others (2003) but not in male fish from the reference site in Overton Arm. Water samples collected from Las Vegas Wash and Bay in 1997 contained feminizing compounds such as $17 \beta$-estradiol (natural estrogen) and $17 \alpha$-ethynylestradiol (a synthetic estrogen used in oral contraceptives), but samples from references sites (Callville Bay) tested negative for these compounds (Snyder and others, 2001). Bevans and others (1996) had previously reported the presence of several other synthetic estrogens (xenoestrogens) in Las Vegas Wash and Bay during 1995. Although the specific compound(s) that are causing the altered reproductive condition in male fish from Las Vegas Bay can not be identified yet, ongoing studies of Lake Mead are being conducted by the Federal government to help answer this question. Most of the evidence from laboratory and field studies suggests that xenoestrogens are a primary cause of feminization of male fish (Sumpter and Johnson, 2005).

\section{Ongoing Studies of Endocrine Disruption}

Since the previous studies of Lake Mead were completed, the southwest region of the United States has been experiencing a drought that has caused current lake levels to be at historic lows. This change in limnological conditions could potentially exacerbate or change the patterns of contaminant distribution and endocrine disruption in Las Vegas Bay and other sites of the lake. Moreover, wastewater dischargers plan to divert a majority of their wastewater from Las Vegas Wash and discharge it through a submerged pipeline in the Boulder Basin (fig. 1). The pipeline will include a discharging diffuser designed to provide the capability to discharge wastewater at a number of depths, including depths below the thermocline and photic zone. This change might result in wastewater being introduced for the first time into new parts of the LMNRA. New studies 


\section{Current Knowledge of Endocrine Disruption}

- Studies conducted in 1995 and 1999-2000 showed that male carp from Las Vegas Bay have low blood levels of androgen and smaller testes compared to male fish from reference sites.

- The same studies and others also showed the presence of higher levels of synthetic chemicals in water, sediment and fish from Las Vegas Bay compared to reference sites.

- Commonly used products known as emerging contaminants, such as triclosan (an antimicrobial drug), are being accumulated in fish from Las Vegas Bay.

- Some of the chemicals present in Las Vegas Bay have been shown by laboratory studies to cause endocrine disruption in male fish.

are now in place to (1) assess the potential effects of droughtinduced alterations in the hydrology of the lake, and (2) provide baseline information to monitor changes in contaminant distribution and potential for endocrine disruption that may occur due to the redistribution of wastewater inflow sites in the Lake Mead and Colorado River ecosystems. These new studies are wider in geographic and scientific scope and address not only endocrine disruption and the presence and distribution of chemical contaminants, but also contaminant sediment flux and microbiology, food web dynamics, and wastewater treatment effects. Such comprehensive studies have never been conducted within the LMNRA.

\section{References}

Bevans, H.E., Goodbred, S.L., Miesner, J.F., Watkins, S.A., Gross, T.S., Denslow, N.D., and Schoeb, T., 1996, Synthetic organic compounds and carp endocrinology and histology in Las Vegas Wash and Las Vegas and Callville Bays of Lake Mead, Nevada, 1992 and 1995: U.S. Geological Survey, Water-Resources Investigations Report 96-4266, 12 p.

Boyd, R.A., and Furlong, E.T., 2002, Human-Health Pharmaceutical Compounds in Lake Mead, Nevada and Arizona, and Las Vegas Wash, Nevada, October 2000-August 2001: U.S. Geological Survey Open-File Report 02-385.

Covay, K.J., and Leiker, T.J., 1998, Synthetic organic compounds in water and bottom sediment from streams, detention basins, and sewage-treatment plant outfalls in Las Vegas Valley, Nevada, 1997: U.S. Geological Survey Open-File Report 98-633, 15 p.
Covay, K.J., and Beck, D.A., 2001, Sediment-deposition rates and organic compounds in bottom sediment at four sites in Lake Mead, Nevada, May 1998: U.S. Geological Survey Open-File Report 01-282, 34 p.

Goodbred, S.L., Leiker, T.J., Patiño, R., Jenkins, J.A., Denslow, N.D., Orsak, E., and Rosen, M.R., 2007, Organic chemical concentrations and reproductive biomarkers in common carp (Cyprinus carpio) collected from two areas in Lake Mead, Nevada, May 1999 through May 2000: U.S. Geological Survey Data Series 286, 18 p.

LaBounty, J.F., and Horn, M.J., 1997, The influence of drainage from Las Vegas Valley on the limnology of Boulder Basin, Lake Mead, Arizona-Nevada: Journal of Lakes and Reservoir Management, v. 13, p. 95-108.

Patiño, R., Goodbred, S.L., Draugelis-Dale, R., Barry, C.E., Foott, J.S., Wainscott, M.R., Gross, T.S., and Covay, K.J., 2003, Morphometric and histopathological parameters of gonadal development in adult common carp from contaminated and reference sites in Lake Mead, Nevada: Journal of Aquatic Animal Health, v. 15. p. 55-68.

Preissler, A.M., Roach, G.A., Thomas, K.A., and Wilson, J.W., 1999, Water Resources Data, Nevada Water Year 1998: U.S. Geological Survey Water Data Report NV-98-1.

Schulz, R.W., and Miura, T., 2002, Spermatogenesis and its endocrine regulation: Fish Physiology and Biochemistry, v. 26, p. $43-56$.

Snyder, S.A., Villeneuve, D.L., Snyder, E.M., and Giesy, J.P., 2001, Identification and quantification of estrogen receptor agonists in wastewater effluents: Environmental Science and Technology, v. 35 , p. $3620-3625$.

\section{Collaboration within the Lake Mead Project}

The results obtained from the ongoing projects are expected to greatly expand baseline chemical and biological data that will assist in management decisions and future monitoring efforts. The studies are being led by the USGS in partnership with the U.S. Fish and Wildlife Service; National Park Service; Bureau of Reclamation; University of Nevada, Las Vegas; University of Nevada, Reno, Desert Research Institute; and Texas Tech University.

\section{For further information about this study, contact}

Michael R. Rosen, Research Hydrologist

USGS Nevada Water Science Center

2730 North Deer Run Road

Carson City, NV 89701

Telephone: 775-887-7683

Fax: 775-887-7629

Email: mrosen@usgs.gov 